\title{
A Phytochemical and Biological Investigation of Some Plants Belong to Cycadales Order Cultivated in Egypt
}

\author{
Walaa Negm, Kamilia Abo El-Seoud, Amal Kabbash and Mona El-Aasr \\ Department of Pharmacognosy, Faculty of Pharmacy, Tanta University, Egypt
}

\section{III}

Background: Gymnosperms are naked seed-producing plants and still a dark area in scientific researches although they considered as a rare gift of the nature. Cycads are one of the largest groups of living Gymnosperms. The three extant families of Cycadales are Cycadaceae, Stangeriaceae, and Zamiaceae. According to review of literature, availability of the plants in Egypt, preliminary phytochemical screening of leaves of some plants of gymnosperms belong to Cycadals order, and the results of biological screening, six plants were chosen to be our target of this study. These plants were Cycas pectinata and Cycas thoursaii (Family Cycadacea), Dioon spinulosum, Dioon mejiae, Dioon merolae and Encephalartous laurantianous (Family Zamiaceae). Aim: The study has been classified into two parts: 1) Preliminary biological and phytochemical screening of leaves of the six plants. 2) Biological activities and phytochemical investigation of the leaves of Dioon spinulosum, the most active plant. Biological investigation of six plants belonging to Cycadals order cultivated in Egypt. Materials and Methods: Antioxidant activity was investigated using different methods: a) Bleomycin-dependent DNA damage, b) ABTS method, c) Assay for erythrocyte hemolysis. For antimicrobial activity, all the plants extracts were individually evaluated for in vitro antibacterial activity against Gram-positive bacteria (Staphylococcus aureus and Bacillus subtilis) and Gram-negative bacteria (Escherichia coli and Pseudomonas aeuroginosa). The anti-fungal activity was tested against two fungi (Candida albicans and Aspergillus flavus). For biological investigation of $D$. spinulosum leaves extract. Activity of D. spinulosum total methanol extract, pet-ether, methylene chloride, ethyl acetate and n-butanol fractions were investigated. For biological investigation of pure isolated compounds from $D$. spinulosum, nine compounds were subjected to further investigation for antioxidant and cytotoxic activities. Results: Dioon spinulosum showed significant activity among investigated compounds. Phytochemical investigation of D. spinulosum leaves resulted in isolation of two new flavonoids, apigenin 7-O-a-D-glucopyranoside and amentoflavone 7- O- $\alpha$-L-rhamnopyranoside, in addition to fifteen known compounds: phytone, trans-phytol $\beta$-sitosterol, stigmasterol, oliveriflavone, 7,7",4',4"' tetra-O-methyl amentoflavone, 7,7",4' tri-O-methyl amentoflavone, scaidopitysin, bilobetin, isoginkgetin, aromadendrin, sotusflavone, engeletin, and eriocitrin for the first time together with amentoflavone. Secondary metabolites isolated from D. spinulosum displayed the highest protective activity against DNA damage, higher than the positive control. A promising future may await D. spinulosum in drug discovery. Conclusion: Results from this study clearly demonstrated that $D$. spinulosum total methanol extract offered an evident for its improvement in the hepatocyte structural changes.

Keywords: Apigenin 7-O-a-D-glucopyranoside; Amentoflavone 7- O- $\alpha$-L-rhamnopyranoside; Biflavonoids; Cycas; Dioon spinulosum

Editor-in-Chief: Prof. M.L. Salem, PhD - Article DOI: 10.21608/jcbr.2021.57862.1119 